Kumawula, Vol. 2, No.2, Agustus 2019, Hal 104 - 116 DOI:http://10.24198/kumawula.v1i3.23566 ISSN 2620-844X (online)

Tersedia online di http://jurnal.unpad.ac.id/kumawula/index

\title{
Pelaksanaan Assertiveness Training Pada Anak Berhadapan dengan Hukum (ABH) di LPKA Bandung
}

\author{
Mutiara Ayu Lestari', Meilanny Budiarti Santoso² \\ ${ }^{1,2}$ Departemen Kesejahteraan Sosial, Fakultas Ilmu Sosial dan Ilmu Politik, Universitas Padjadjaran \\ ${ }^{1}$ mutiaraayulestari36@gmail.com,2meilannybudiarti13@gmail.com
}

\begin{abstract}
ABSTRAK
Jumlah Kasus Anak berhadapan dengan Hukum (ABH) setiap tahunnya terus mengalami peningkatan. Pada Tahun 2018, tercatat ada sebanyak 1434 kasus pengaduan Anak Berhadapan dengan Hukum yang diperoleh oleh Komisi Perlindungan Anak Indonesia (KPAI). Terdapat berbagai faktor yang berkontribusi sebagai penyebab terjadinya kasus Anak Berhadapan Dengan Hukum (ABH). Faktor yang paling mendominasi peningkatan $\mathrm{ABH}$ adalah pengaruh dari teman dan pergaulan. Teknik Assertiveness Training diterapkan sebagai upaya pencegahan peningkatan kasus Anak Berhadapan dengan Hukum melalui pemberian pemahaman kepada para anak didik (ANDIK) di LPKA Bandung mengenai penerapan perilaku asertif dalam kehidupan sehari-hari. Tujuan dari kegiatan ini adalah agar para ANDIK dapat memahami dampak dari 3 sikap dalam assertiveness training yaitu aggressive, non assertive dan assertive. Hal ini dilakukan karena sangat penting bagi seorang individu untuk menerapkan perilaku asertif dalam aktivitas sehari-hari terutama ketika seorang individu berada di dalam lingkungan masyarakat. Assertiveness Training dilakukan sebagai salah satu rangkaian kegiatan pengabdian mahasiswa kepada para generasi penerus bangsa. Teknik Assertiveness Training dilakukan melalui metode Social Group Work bersama para ANDIK LPKA Bandung.
\end{abstract}

Kata Kunci: Anak Berhadapan dengan hukum, LPKA, Assertiveness Training

\section{Implementation of Assertiveness Training For Children Dealing With The Law (ABH) in LPKA Bandung}

\begin{abstract}
The cases of children dealing with the law $(A B H)$ continues to increase every year. In 2018, there were 1434 cases of Children dealing with the Law that were received by the Indonesian Child Protection Commission (KPAI). Various factors contributed as a cause of Children dealing with the Law (ABH), the most dominant factor that increased the case of children dealing with the law is the influence of friends and relationships. Assertiveness Training Technique is applied as an effort to prevent the increase of cases of Children dealing with the Law through providing understanding in LPKA Bandung regarding the application of assertive behavior in their daily lives. The purpose of this activity is that the Children can understand the impacts of 3 attitudes in assertiveness training, namely aggressive, non-assertive and assertive. This is done because an individual needs to implement assertive behavior in daily activities, especially when an individual is in a community. The Assertiveness Training is conducted as a series of social welfare programs by Padjadjaran University Social Welfare Students and also a form of devotion to the next generation of the nation. The Assertiveness Training technique is carried out through the Social Group Work method alongside the ANDIK LPKA Bandung.
\end{abstract}

Keywords : Children dealing with the law, LPKA, Assertiveness Training 


\section{PENDAHULUAN}

Pada umumnya vpara Anak berhadapan dengan Hukum (ABH) di Lembaga Pembinaan Khusus Anak (LPKA) tidak lagi berada pada masa anak-anak. Para ABH umumnya berada pada masa remaja. Masa remaja menjadi salah satu periode perkembangan dan pasti dialami oleh setiap individu dalam rangka menuju kedewasaan. Kata "Remaja" berasal dari Bahasa Latin yaitu “adolescere” yang memiliki arti tumbuh ke arah menuju kematangan (Muss, 1968 dalam Sarwono, 2011: h.11). Dalam hal ini kematangan yang dimaksud meliputi kematangan secara fisik, sosial dan juga psikologis.

Pada tahun 1974 World Health Organization (WHO) mendefinisikan remaja yang meliputi biologis, psikologis dan sosial ekonomi. Definisi tersebut dikatakan sebagai berikut bahwa remaja adalah suatu masa yang mana (Sarwono, 2011):

1. Individu berkembang pada saat pertama kali ia menunjukan tanda-tanda seksual sekundernya sampai saat ia mencapai kematangan sosial (Secara biologis).

2. Individu mengalami perkembangan dan pola identifikasi dari anak-anak menjadi dewasa (Secara sosial- psikologis).

3. Terjadi peralihan dari ketergantungan sosial-ekonomi yang penuh kepada keadaan yang relative lebih mandiri (Secara sosial-ekonomi).

Masa remaja menjadi periode dimana seorang individu ada diambang perbatasan karena mereka tidak lagi berada dalam masa anak-anak namun juga tidak dapat dikatakan sebagai orang dewasa. Monks (dalam Yusuf, 2005) membagi masa remaja menjadi 3 masa kelompok usia yaitu sebagai berikut:

1. Remaja awal yang berusia 12-15 tahun. Masa ini disebut masa negatif. Dimana remaja merasa bingung, cemas, gelisah dan takut.

2. Remaja pertengahan yang berusia $15-18$ tahun. Pada masa ini remaja menginginkan dan mencari-cari sesuatu. Pada masa ini individu memikirkan konsep diri.

3. Remaja akhir yang berusia 18-21 tahun. Pada masa ini remaja mulai merasa stabil. Remaja memulai mengenal dirinya, memahami arah hidup dan menyadari tujuan hidupnya.

Hurlock (1990) juga mendefinisikan masa remaja menjadi dua masa yaitu ketika seorang individu berada pada usia 11-12 tahun - 16-17 tahun dan masa remaja akhir ketika seorang individu berada pada usia 16-17 tahun - 17-18 tahun.

Berdasarkan data dari pihak Lembaga Pembinaan Khusus Anak (LPKA) kota Bandung, dapat dilihat bahwa secara keseluruhan para $\mathrm{ABH}$ berada dalam usia masa remaja karena berada 
di usia antara 14 tahun hingga $>18$ Tahun.

\section{Grafik 1}

Klasifikasi Usia Anak Berhadapan dengan Hukum di LPKA Kota Bandung

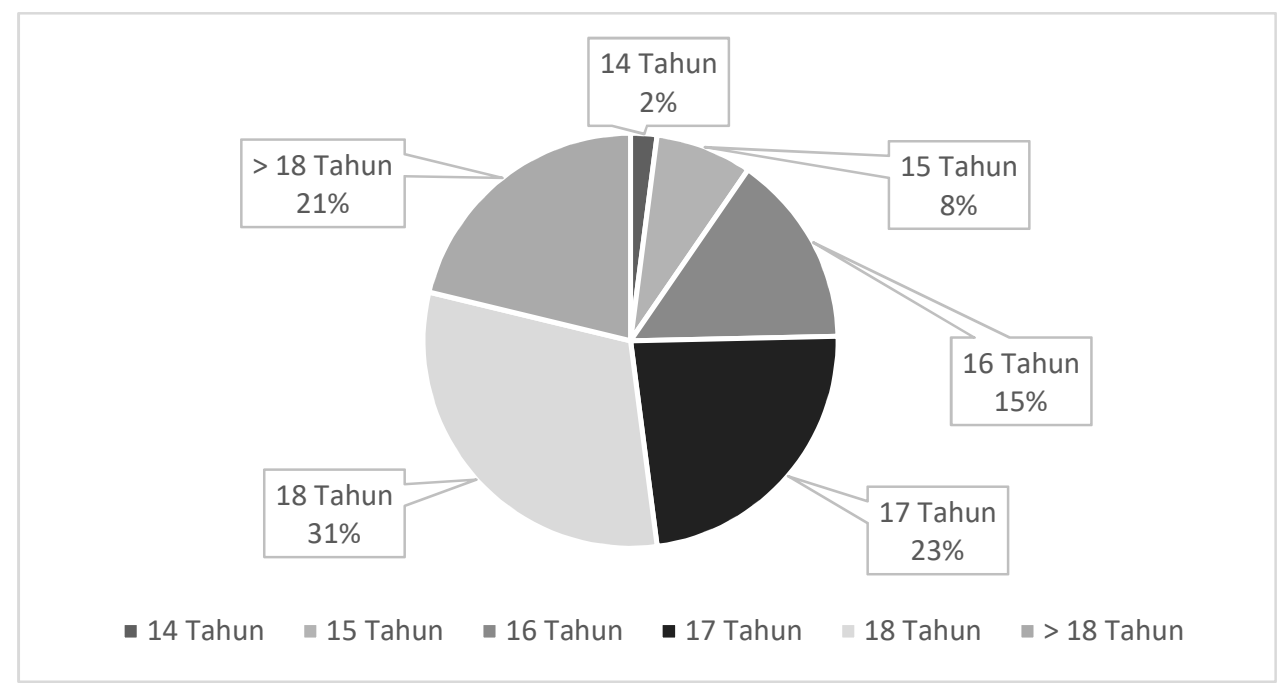

Sumber: Jurnal Harian LPKA Bandung Maret 2019

Masa remaja adalah suatu periode yang paling berpengaruh dalam kehidupan manusia, suatu masa transisional, masa perubahan, masa bermasalahan, masa mencari identitas, usia menyeramkan, masa unrealism dan masa menuju kedewasaan (Krori, 2011). Masa remaja menurut Hall (Sarwono, 2011) juga dikatakan sebagai periode "strum und drang" yaitu masa topan dan badai. Masa dimana individu penuh emosi dan ada saatnya emosi tersebut meledakledak, yang muncul karena adanya pertentangan nilai. Krori (2011) juga mengatakan bahwa pada masa remaja terjadi perubahan sosial penting yang salah satunya meliputi terjadinya peningkatan pengaruh dari teman sebaya (peer group) individu.

Pada masa ini individu berusaha untuk mencari identitasnya dan terkadang harus menghadapi permasalahan dalam prosesnya. Tidak jarang seorang remaja melakukan tindakan yang merugikan orang lain, hal itu bisa disebut sebagai kenakalan remaja. Setiap tindak kenakalan remaja pasti akan mendapatkan sanksi baik berupa sanksi sosial bahkan sanksi hukum berupa penahanan. Pada tanggal 30 juli 2012, DPR RI mengesahkan Undang-undang Nomor 11 Tahun 2012 tentang Sistem Peradilan Pidana Aanak (UU SPPA) yang mulai diberlakukan sejak tanggal 31 Juli 2014. Dibentuknya Undang-undang ini bertujuan agar dapat terwujudnya peradilan yang benar-benar menjamin adanya perlindungan kepentingan terbaik terhadap anak yang berhadapan dengan hukum.

Seorang anak yang sedang menjalani proses peradilannya akan ditempatkan di Lembaga Pembinaan Khusus Anak (LPKA), hal tersebut sesuai dengan pasal 85 dalam UU SPPA yang 
berbunyi:

1. Anak yang dijatuhi pidana penjara ditempatkan di LPKA

2. Anak sebagaimana dimaksut pada ayat (1) berhak memperoleh pembinaan, pembimbingan, pengawasan, pendampingan, pendidikan dan pelatihan, serta hak lain sesuai dengan peraturan perundang-undangan;

3. UU SPPA yang menyatakan LPKA wajib menyelenggarakan pendidikan, pelatihan, keterampilan, pembinaan dan pemenuhan hak lain sesuai dengan ketentuan peraturan perundang-undangan;

4. Pembimbing kemasyarakatan melakukan penelitian kemasyarakatan untuk menentukan penyelenggaraan program pendidikan dan pembinaan sebagaimana dimaksud pada ayat (3)

5. Balai Pemasyarakatan (Bapas) wajib melakukan pengawasan terhadap pelaksanaan program sebagaimana dimaksud pada ayat (4)

LPKA juga memulai untuk memanggil para $\mathrm{ABH}$ disana dengan sebutan ANDIK yang merupakan singkatan dari Anak Didik. Karena sewaktu berada di LPKA, para ABH akan memperoleh pendidikan dan pembinaan dari pihak LPKA. LPKA Kota Bandung yang bertempat di jalan Arcamaik diresmikan pada tanggal 5 Agustus 2015 oleh Direktorat Jendral Pemasyarakatan. Dan pada saat ini LPKA Kota Bandung menampung sebanyak 146 Anak berhadapan dengan hukum.

Seperti yang sudah dikatakan sebelumnya bahwa faktor yang mendominasi terus terjadinya peningkatan kasus $\mathrm{ABH}$ adalah pertemanan dan lingkungan sekitar. Teman sebaya dan lingkungan pertemanan sangat mempengaruhi perkembangan diri individu pada masa remaja. Dari beberapa hasil assessment yang dilakukan kepada para Anak didik LPKA Bandung, beberapa mengatakan bahwa terkadang mereka sulit untuk menolak (non assertive) ajakan teman atau kelompok meskipun mereka mengetahui ajakan tersebut tergolong tindakan yang negatif adapula yang seringkali memiliki emosi yang meledak-ledak ketika menghadapi permasalahan (aggressive). Dari hasil assessment tersebut, tim pelaksana kegiatan pengabdian pada masyarakat ingin memberikan pemahaman dan menanamkan karakter asertif kepada para ANDIK di LPKA Bandung sebagai salah satu upaya preventif peningkatan kasus $\mathrm{ABH}$ di Indonesia. Perilaku asertif atau assertiveness dapat didefinisikan sebagai bentuk komunikasi atau ekspresi diri seseorang secara langsung dan jujur namun tetap menghargai Hak Asasi Manusia (HAM) dan martabat orang lain. Pemberian informasi mengenai perilaku asertif dapat dilakukan dengan menggunakan teknik assertiveness training. Assertiveness Training sendiri 
merupakan bentuk treatment yang dapat dilakukan dalam praktik pekerjaan sosial. Asertiveness training memiliki prinsip dasar bahwa semua manusia mempunyai hak untuk menyampaikan pemikiran, perasaan dan kebutuhannya kepada orang lain namun dengan cara yang tepat. Terdapat tiga pengetahuan yang akan diberikan dalam pelaksanaan assertiveness training yaitu informasi mengenai sikap aggressive, non assertive dan assertive.

Tabel 1

Ciri-Ciri Tiga Perilaku Dalam Teknik Assertiveness Training

\begin{tabular}{|c|c|c|}
\hline $\begin{array}{c}\text { NON-ASSERTIVE } \\
\text { (submissive) }\end{array}$ & AGGRESSIVE & ASSERTIVE \\
\hline $\begin{array}{l}\text { 1. Bicara pelan (nyaris } \\
\text { tidak terdengar) } \\
\text { 2. Pandangan menghindar } \\
\text { 3. Menghindar masalah/isu } \\
\text { 4. Menyetujui dengan tidak } \\
\text { memeperdulikan } \\
\text { perasaan sendiri } \\
\text { 5. Memberikan pendapat } \\
\text { dengan tidak jelas/tegas } \\
\text { 6. Menilai diri sendiri lebih } \\
\text { rendah dari yang lain } \\
\text { 7. Menyakiti diri sendiri } \\
\text { untuk menghindari } \\
\text { kemungkinan menyakiti } \\
\text { roang lain }\end{array}$ & $\begin{array}{l}\text { 1. Memotong sebelum } \\
\text { orang lain } \\
\text { menyelesaikan } \\
\text { pembicaraannya } \\
\text { 2. Berbicara dengan keras } \\
\text { dan kasar } \\
\text { 3. Pandangan menyorot / } \\
\text { melotot } \\
\text { 4. Berbicara melampaui isu } \\
\text { yang dibahas } \\
\text { (menyalahkan / } \\
\text { merendahkan) } \\
\text { 5. Menjelaskan pendapat } \\
\text { dan apa yang dirasakan } \\
\text { dengan berapi-api } \\
\text { 6. Menilai orang lain lebih } \\
\text { rendah dari diri kita } \\
\text { sendiri } \\
\text { 7. Menyakiti orang lain } \\
\text { untuk menghindari } \\
\text { tersakitinya diri sendiri }\end{array}$ & $\begin{array}{l}\text { 1. Menjawab secara } \\
\text { spontan, berbicara } \\
\text { dengan tekanan dan } \\
\text { volume suara percakapan } \\
\text { 2. Melihat / menatap lawan } \\
\text { bicara } \\
\text { 3. Berbicara pada isu } \\
\text { 4. Secara terbuka } \\
\text { mengungkapkan pendapt } \\
\text { dana pa yang dirasakan } \\
\text { (marah, cinta } \\
\text { ketidaksetujuan dan } \\
\text { kesedihan) } \\
\text { 5. Menilai diri sendiri } \\
\text { setara dengan orang lain } \\
\text { 6. Menghindari untuk tidak } \\
\text { menyakiti diri sendiri } \\
\text { maupun orang lain }\end{array}$ \\
\hline
\end{tabular}

Sumber: Taftazani, 2019

\section{METODE}

Sebagai upaya mencapai tujuan dari kegiatan assertiveness training, maka pelaksanaan kegiatan dilakukan menggunakan metode social group work: educational. Social group work merupakan sebuah metode dalam praktik pekerjaan sosial yang memiliki tujuan untuk meningkatkan keberfungsian sosial individu menggunakan kelompok sebagai media pertolongan.

Assertiveness training termasuk ke dalam teknik social group work: educational karena ketika individu mengikuti group work tersebut, ia akan memperoleh pengetahuan dan keterampilan mengenai perilaku asertif. Ada beberapa cara bimbingan yang dapat digunakan 
dalam social group work antara lain melalui diskusi kelompok, bermain peran (role play), studi kasus, brain storming dan wawancara kelompok. Dalam kegiatan assertiveness training bersama para ANDIK di LPKA Bandung, tim pelaksana kegiatan pengabdian pada masyarakat menggunakan role play sebagai cara bimbingan social group work. Role play sendiri merupakan suatu teknik dalam social group work yang dilakukan dengan memainkan peran tertentu dengan tujuan memberikan ruang kepada seluruh anggota kelompok untuk berekspresi sebagaimana mestinya mereka menentukan sikap apabila dihadapkan pada suatu permasalahan.

Secara umum pelaksanaan kegiatan dilakukan melalui beberapa tahapan mulai dari perizinan lembaga, persiapan kegiatan pengabdian pada masyarakat, rangkaian pelaksanaan kegiatan group work: assertiveness training dan evaluasi kegiatan.

Tabel 2.2

Tahapan-Tahapan Pelaksanaan Kegiatan di LPKA Bandung

\section{PERIZINAN LEMBAGA ( 20 Februari 2019 \& 4 Maret 2019)}

1. Mendatangi LPKA Bandung dan bertanya mengenai tata cara dan persyaratan melakukan praktikum di LPKA untuk mengajukan perizinan praktikum.

2. Mengajukan surat izin praktikum kepada SBA FISIP Universitas Padjadjaran

3. Pengambilan Surat izin praktikum dari Kantor Wilayah KEMENKUMHAM Jawa Barat dan menyerahkannya kepada pihak LPKA Bandung. Kemudian praktikan bertemu dengan perwakilan dari pihak LPKA yang akan menjadi supervisor kami selama proses praktikum berlangsung.

\section{PERSIAPAN KEGIATAN PENGABDIAN ( 11 - 29 Maret 2019)}

1. Penyampaian informasi oleh LPKA Bandung mengenai hal-hal yang berkaitan dengan proses praktikum (Di dalam ruang kelas LPKA Bandung).

2. Pertemuan antara dosen supervisior dan supervisior dari LPKA untuk menjelaskan maksud dan tujuan praktikum.

\section{RANGKAIAN KegIATAN PENGABDIAN ( 2 April 2019 \& 26 April 2019 )}

1. Dilakukan social group work : recreational skills group untuk mencairkan suasana pertemuan pertama antara ANDIK LPKA Bandung dengan praktikan.

2. Pertemuan kembali antara praktikan dan ANDIK LPKA Bandung dengan sesi mikro. (Satu praktikan akan berhadapan dengan satu ANDIK LPKA Bandung (Tahap Assesment). 


\section{PELAKSANAAN KEGIATAN ASSERTIVENESS TRAINING ( 10 May 2019 )}

1. Dilakukan dalam social group work di lapangan sepak bola LPKA Bandung.

2. Dilakukan evaluasi setelah kegiatan untuk mengetahui goals yang berhasil dicapai serta kekurangan sewaktu pelaksanaan kegiatan.

Sumber : Pelaksanaan Pengabdian pada Masyarakat Mahasiswa Kesejahteraan Sosial Unpad, 2019.

\section{HASIL DAN PEMBAHASAN}

\section{A. Pelaksanaan Kegiatan Assertiveness Training}

Seperti yang sudah dijelaskan sebelumnya bahwa kegiatan assertiveness training termasuk ke dalam rangkaian pengabdian pada masyarakat. Pelaksanaan Assertiveness Training dilakukan pada hari Jumat 10 May 2019. Assertiveness training menjadi salah satu kegiatan outdoor yang dilakukan bersama para ANDIK karena dilaksanakan di Lapangan sepak bola LPKA Bandung. Pelaksanaan kegiatan berdurasi sekitar 1,5 jam.

Kegiatan assertiveness training diikuti oleh 12 orang ANDIK LPKA Bandung dan tim pelaksana kegiatan pengabdian pada masyarakat. Pelaksanaan assertiveness training dilakukan dalam bentuk bermain peran (role play), hal ini dipilih agar pemberian pemahaman kepada para ANDIK tidak terlalu bersifat formal, memberikan ruang bagi para ANDIK untuk mengekspresikan dirinya, bisa mengamati karakter dari para ANDIK dan pengaplikasian langsung dalam isu-isu yang terjadi dalam masyarakat. Ada beberapa tahapan yang dapat dilakukan pada pelaksanaan teknik assertiveness training.

Langkah pertama, Melakukan pengarahan (briefing) kepada seluruh tim pelaksana kegiatan pengabdian pada masyarakat yang hadir. Tim pelaksana mendiskusikan bentuk pelaksanaan teknik assertiveness training, membuat rundown acara, menentukan lokasi pelaksanaan dan juga menentukan isu-isu yang akan diangkat sebagai tema role play para ANDIK. Kemudian melakukan pembagian tugas kepada anggota tim pelaksana kegiatan menjadi 3 kelompok yaitu fasilitator, pembawa acara dan pengamat. Hal ini dilakukan agar setiap tim pelaksana kegiatan pengabdian pada masyarakat mempunyai tugas yang jelas selama kegiatan berlangsung. Tim pelaksana kegiatan yang menjadi fasilitator bertugas untuk membaur ke dalam kelompok para ANDIK dan mendampingi kelompok tersebut selama kegiatan assertiveness training berlangsung. Para fasilitator juga bertugas sebagai pencair 
suasana dalam kelompok. Tim pelaksana kegiatan pengabdian pada masyarakat yang menjadi pembawa acara bertugas untuk memimpin dan melakukan controlling terhadap jalannya kegiatan agar sesuai dengan rundown yang telah dibuat. Tim pelaksana kegiatan pengabdian pada masyarakat yang menjadi pengamat bertugas untuk mengamati dan mencatat perilaku dari setiap ANDIK yang mengikuti kegiatan assertiveness training. Hal ini dilakukan untuk mengetahui karakteristik dari setiap ANDIK agar memudahkan tim pelaksana kegiatan pengabdian pada masyarakat ketika nantinya ingin menentukan metode intervensi yang sesuai untuk para ANDIK dalam sesi mikro. Tim pelaksana kegiatan pengabdian pada masyarakat yang menjadi pengamat harus bersifat objektif selama kegiatan assertiveness training berlangsung.

Langkah Kedua, Membuat barisan rapih beberapa banjar untuk membagi para ANDIK menjadi beberapa kelompok. Dikarenakan jumlah ANDIK yang hadir sebanyak 12 orang, maka dibuat 4 kelompok dengan 1 kelompok terdiri oleh 3 orang ANDIK. Pembagian ini dilakukan dengan cara berhitung mulai dari 1 sampai 4 kemudian mereka yang memiliki angka yang sama akan menjadi satu kelompok. Setiap kelompok terdiri dari 3 ANDIK dan 2 orang tim pelaksana kegiatan pengabdian sebagai fasilitator kelompok. Kemudian tim pelaksana kegiatan pengabdian, fasilitator membaur bersama 4 kelompok ANDIK yang telah terbentuk.

Langkah Ketiga, Pembawa acara memberikan penjelasan mengenai kegiatan yang akan dilakukan. Pembawa acara memberikan informasi bahwa kegiatan hari ini adalah bermain peran (role play). Namun belum dijelaskan apa sebenarnya nama dan tujuan dari kegiatan ini. Setiap kelompok akan diberikan sebuah isu yang sering terjadi di masyarakat, kemudian mereka harus memberikan respon terhadap isu tersebut. Fasilitator bertugas untuk menjelaskan kembali secara lebih detail mengenai kegiatan role play. Terdapat 4 isu yang diangkat untuk setiap kelompok yaitu sebagai berikut:

1. Bagaimana respon kalian (ANDIK) jika kalian sedang ada dalam transportasi umum (kereta), kemudian ada seseorang yang merokok dalam sarana transportasi umum tersebut?

2. Bagaimana respon kalian (ANDIK) jika kalian sedang belajar namun ada teman yang mengajak bermain?

3. Bagaimana respon kalian (ANDIK) jika melihat seorang perempuan sedang dipukuli oleh seorang laki-laki?

4. Bagaimana respon kalian (ANDIK) jika kalian sedang berada dalam kamar (karena di LPKA, 1 kamar diisi oleh +10 orang) kemudian ada seseorang yang sangat berisik? 
Langkah Keempat, Pembagian isu dan Diskusi kelompok mengenai role play yang akan dilakukan. Setelah setiap kelompok mendapatkan satu isu maka mereka langsung diajak untuk berdiskusi tentang apa yang akan mereka lakukan dan apa peran yang akan dimainkan oleh setiap anggota kelompok. Contohnya seperti role play pada isu pertama yaitu "Bagaimana respon kalian (ANDIK) jika kalian sedang ada dalam transportasi umum (kereta), kemudian ada seseorang yang merokok dalam sarana transportasi umum tersebut?”. Kelompok yang mendapatkan isu tersebut membagi anggotanya menjadi tiga bagian yaitu 2 orang sebagai pengguna kereta biasa, 1 orang sebagai pengguna kereta dan merokok serta 2 orang sebagai responden yang menanggapi perilaku tersebut. Diskusi kelompok dilakukan selama beberapa menit agar setiap anggota dapat menyampaikan pendapatnya. Selain itu dari diskusi ini juga dapat membangun kebersamaan dan keakraban diantara para ANDIK LPKA.

Langkah kelima, Menampilkan hasil diskusi kelompok di depan tim pelaksana kegiatan pengabdian pada masyarakat dan ANDIK. Setelah berdiskusi maka setiap kelompok harus menampilkan role play dari hasil diskusinya mengenai isu yang telah diberikan. Penentuan urutan tampil dilakukan dengan cara "gambreng" oleh satu orang perwakilan kelompok.

Hampir setiap kelompok melakukan role play dengan cara membagi anggotanya menjadi dua model peran yaitu pelaku dan responden. Sebelum memulai role play, setiap kelompok harus memperkenalkan diri dan peran mereka dalam role play tersebut.

Seperti yang dilakukan oleh kelompok 1 yaitu "Bagaimana respon kalian (ANDIK) jika kalian sedang ada dalam transportasi umum (kereta), kemudian ada seseorang yang merokok dalam sarana transportasi umum tersebut?" Mereka menampilkan role play dengan membagi orang anggota kelompok menjadi menjadi tiga bagian yaitu 2 orang sebagai pengguna kereta biasa, 1 orang sebagai pengguna kereta dan merokok serta 2 orang sebagai responden yang menanggapi perilaku tersebut. Mereka memperagakan situasiseperti berada dalam kereta. Dengan posisi berdiri dan tangan kiri ke atas seakan-akan mereka sedang menggenggam tali pegangan dalam kereta api. Kemudian salah satu dari mereka mulai mempergakan adegan merokok dan 2 orang pengguna lain mulai memperagakan sikap terganggu seperti berkipas-kipas disekitar hidung. Lalu datang 2 orang responden untuk memberitahu pelaku merokok dengan sangat sopan untuk mematikan rokoknya karena kereta api merupakan transportasi umum. Dan sang perokok pun mendengarkan perkataan dua responden tersebut lalu mematikan rokok yang sedang dihisapnya. Kemudian kelompok tersebut mengucapkan terima kasih dan kembali duduk 
ditempat semula.

Pelaksanaan role play berjalan dengan baik, meskipun tidak semua ANDIK berani tampil dan dapat mengekspresikan pendapatnya. Bahkan ada juga kelompok yang pasif dan masih bingung role play apa yang akan ditampilkan. Namun sudah banyak dari mereka yang menerapkan perilaku asertif ketika berada dalam role play tersebut.

Langkah keenam adalah memberikan penjelasan kepada para ANDIK mengenai role play yang baru saja dilakukan. Penyampian informasi mengenai role play tersebut dijelaskan oleh pembawa acara. Pertama-tama pembawa acara mengapresiasi setiap kelompok yang telah mengikuti kegiatan. Kemudian para ANDIK diberitahu bahwa mereka baru saja melakukan assertiveness training. Para ANDIK diberitahu mengenai tiga ciri-ciri perilaku dalam teknik assertiveness Training yaitu sebagai berikut:

Tim pelaksana kegiatan pengabdian pada masyarakat memberitahu bahwa akan lebih baik jika para ANDIK dapat merespon setiap kejadian yang sedang dihadapi dengan perilaku asertif. Karena dalam role play tersebut sudah nampak jelas bagaimana dampak dan akibat yang akan terjadi jika seseorang merespon dengan perilaku agresif ataupun non asertif.

Sebagai cara memberikan gambaran lebih jelas kepada para ANDIK, pembawa acara bertanya mengenai role play yang telah dilakukan. Seperti sebagai berikut:

"Jika kalian berada dalam kereta tersebut dan ada yang merokok, tapi kalian memberitahu orang tersebut dengan nada marah (aggressive). Menurut kalian orangnya akan marah balik gak?" Dan para ANDIK serempak menjawab "Iya" dan akan menyebabkan keributan.

Pertanyaan selanjutnya "Jika kalian berada dalam kereta tersebut dan ada yang merokok. tapi kalian hanya diam saja, apa yang kalian rasakan?” Para ANDIK menjawab bau asap rokok dan terganggu.

Pertanyaan-pertanyaan diatas bertujuan untuk menunjukan kepada para ANDIK bahwa sangat penting untuk mengemukakan pendapat di setiap permasalahan yang sedang dihadapi. Namun dengan cara penyampaian yang asertif yaitu dengan sopan, tidak menyinggung dan tetap menghargai hak orang lain. Para ANDIK juga dihimbau agar dapat menerapkan perilaku asertif dalam kehidupan sehari-hari, baik ketika mereka berada di dalam lingkungan LPKA ataupun setelah mereka kembali ke dalam lingkungan masyarakat.

\section{B. Evaluasi Kegiatan Assertiveness Training}

Evaluasi dilakukan untuk mengetahui hasil capaian dalam kegiatan dan untuk 
melakukan perbaikan terhadap kegiatan selanjutnya. Untuk mengetahui apakah kegiatan assertiveness training berhasil mencapai tujuan maka setelah role play selesai, seluruh tim pelaksana kegiatan pengabdian pada masyarakat dan ANDIK duduk melingkar terkecuali pembawa acara. Pembawa acara menanyakan kepada para ANDIK adakah yang ingin menyampaikan pesan dan kesan dari adanya kegiatan tersebut. Beberapa orang dari mereka berdiri dan menyampaikan pemikirannya. Mereka yang berdiri menyampaikan bahwa dari kegiatan tersebut, kita harus bersikap sopan kepada orang lain, Jika menegur harus dengan yang sopan karena jika kita tidak sopan bisa terjadi keributan dan jika kita diam saja juga akan merugikan diri kita sendiri (Respon mengenai isu Bagaimana respon kalian (ANDIK) jika kalian sedang ada dalam transportasi umum (kereta), kemudian ada seseorang yang merokok dalam sarana transportasi umum tersebut? dan Bagaimana respon kalian (ANDIK) jika kalian sedang berada dalam kamar (karena di LPKA, 1 kamar diisi oleh +10 orang) kemudian ada seseorang yang sangat berisik?).

Evaluasi juga dilakukan melalui metode casework. Tim pelaksana kegiatan pengabdian pada masyarakat bertanya kepada klien apa yang ia dapat dari kegiatan assertiveness training tersebut. ANDIK tersebut menjawab bahwa setelah ia mengikuti kegiatan assertiveness training, ia belajar bahwa dalam kehidupan sehari-hari ia harus bertindak sopan karena jika bertindak agresif maka perilaku tersebut dapat memancing emosi orang lain dan menyebabkan keributan. ANDIK tersebut juga mengatakan tidak mau lagi bersikap non assertive atau berani mengatakan "tidak" jika ada teman yang mengajak melakukan hal-hal negatif.

Dari perkataan ANDIK tersebut, dapat dikatakan bahwa tujuan dari diadakannya kegiatan assertiveness training sudah berhasil dicapai. Karena ANDIK dapat memahami perbedaan dan dampak dari penggunaan sikap aggressive, assertive dan non assertive.

\section{SIMPULAN}

Pelaksanaan teknik assertiveness training merupakan salah satu rangkaian pengabdian pada masyarakat yang bertujuan untuk membantu ANDIK yang sedang memiliki permsalahan dan juga mengembangkan potensi dari para ANDIK yang berada di LPKA Kota Bandung. Pelaksanaan teknik assertiveness training juga merupakan bentuk pengabdian mahasiswa sebagai upaya menerapkan langsung ilmu yang telah diperolehnya. Teknik assertiveness training dipilih berdasarkan hasil assessment yang dilakukan oleh para tim pelaksana kegiatan kepada ANDIK LPKA Kota Bandung. Pemberian informasi mengenai 3 pengetahuan sikap (aggressive, non assertive, assertive) dalam assertiveness training dirasa sangat penting dalam 
masa remaja sebagai upaya pencegahan terus terjadinya kasus Anak Berhadapan dengan Hukum di Indonesia.

\section{DAFTAR PUSTAKA}

Assertiveness Tarining. (n.d.). Retrieved from http://www.abct.org/docs/factsheets/ASSERTIVENESS.pdf

Halim, D. (2019, January 8). Kasus Anak Berhadapan dengan Hukum Tertinggi, didominasi Kejahatan Seksual. Kompas.com. Retrieved from https://nasional.kompas.com/read/2019/01/08/19381211/kasus-anak-berhadapandengan-hukum-tertinggi-didominasi-kejahatan-seksual

Herlina. (2013). Bibliotheraphy: Mengatasi Masalah Anak dan Remaja melalui Buku. Bandung: Pustaka Cendikia Utama.

Hurlock, E.B. (1990). Developmental Psychology: A Lifespan Approach (Terjemah oleh Istiwidayanti). Jakarta : Erlangga Gunarsa.

Krori, Smita Deb. (2011). Developmental Psychology, dalam Homeopathic Journal Volume: 4, Issue: 3, Jan, 2011. Retrieved : http://www.homeorizon.com/homeopathicarticles/psychology/developmental-psychology

Ramadhani, W. S. (n.d.). Social Group Work. Retrieved from https://www.academia.edu/26053150/SOCIAL_GROUP_WORK

Robbani, D. (n.d.). 8-METODE SOCIAL GROUP WORK. Retrieved from https://www.academia.edu/33342899/8-METODE_SOCIAL_GROUP_WORK.ppt

S, L. M. (2017). Penerapan Metode Pekerja Sosial Dalam Penanganan Anak Berhadapan Hukum Oleh Upt Pelayanan Anak Dan Remaja Kecamatan Tanjung Morawa Kabupaten Deli Serdang. Retrieved from http://repository.usu.ac.id/handle/123456789/66710

Sarwono, S. (2011). Psikologi Remaja. Jakarta: PT. Rajagrafindo Persada.

Taftazani, B. M. (2019). Assertiveness Training. Presentasi Perkuliahan (tidak dipublikasikan).

Wibowo, H. (2017). Praktik Bekerja Bersama Kelompok Untuk Penguatan Program Pelatihan dan Pengembangan. Retrieved from http://jurnal.unpad.ac.id/share/article/view/13823/6631

Y., \& Ernis, Y. (2016). Lembaga Pembinaan Khusus Anak Dalam Perspektif Sistem Peradilan 
Pidana Anak. Retrieved from

http://sipkumham.balitbangham.go.id/assets/img/dokumenpenelitian/PTL2017110901 5102016_A20.pdf

Yusuf, S. (2005). Psikologi Perkembangan Anak dan Remaja. Bandung: PT Remaja Rosdakarya. 